\title{
The Creative Tourist Experience in the Alentejo region: A case study of the CREATOUR project in Portugal
}

\author{
Noémi Marujo ${ }^{1[0000-0001-8058-5130]}$, Jaime Serra 2[0000-0002-0299-4649] \\ and Maria do Rosário Borges ${ }^{3[0000-0003-2519-7535]}$ \\ ${ }^{123}$ CIDEHUS, University of Évora, Largo dos Colegiais, 2; 7000-812 Évora, PORTUGAL \\ noemi@uevora.pt, jserra@uevora.pt, mrborges@uevora.pt
}

\begin{abstract}
Tourism demand for culture-based creative tourism has been triggering growing interest in various research domains. In the context of the CREATOUR project 'Creative Tourism Destination Development in Small Cities and Rural Areas', an exploratory study was conducted in order to describe and analyse the tourist experience in the pilot activities carried out. The profile of the tourists that participated in the creative tourism activities promoted by the CREATOUR pilot in the Alentejo Portuguese region will be under review concerning sociodemographic characteristics, travel behaviour and motivations. To accomplish this objective, a total of 74 surveys were collected in 2018. Results revealed that participants in creative activities are of an active professional age, have a higher level of qualifications and travel with their partners or in an organised group. Regarding their motivations, results also revealed that they seek original experiences and want to stimulate more creative behaviour.
\end{abstract}

Keywords: Alentejo, Creative Tourist, CREATOUR, Experiences.

\section{Introduction}

In parallel with the growth of cultural tourism offer in the Alentejo region, there is an emerging demand for active learning experiences that provide an authentic dive into the local culture, in situ, based on process of co-creation and enabling self-expression and development of creative skills for the visitor. So far, creative tourism development in small cities and rural areas in this region has shown a strong affinity with cultural assets and activities. This trend has attracted the attention of different players, not only due to the opportunity to improve the attractiveness of the destination but also to explore new markets and be commercially successful. But the value creation of these experiences should be based on value networks that are able to promote synergies among the different stakeholders and organisations related to cultural, creative and tourism fields in the region. In Portugal, and particularly as regards the Alentejo, this scenario has recently started and is under construction. This justifies the tourism demand for culture-based creative tourism triggering growing interest from investigators in various research domains. Tracking the profile of tourists who want to experience creative interaction with different cultures and have the opportunity to acquire new learning and intercultural experiences can help producers and places to be more 
attractive and improve the value of their market. To understand this reality in the Alentejo it is necessary to carry out more studies with this approach. Therefore, in the context of the CREATOUR project 'Creative Tourism Destination Development in Small Cities and Rural Areas', an exploratory study was conducted in order to describe and analyse the tourist experience in pilot activities carried out in their communities. In this context, the profile of the tourists that participated in the cultural-based creative tourism activities promoted by the CREATOUR pilot in the Portuguese region of the Alentejo will be under review, concerning sociodemographic characteristics, travel behaviour and motivations. This chapter is organised in 4 sections. After this introduction, a brief literature review on concepts about creative tourism, creative tourism related with culture and creative tourist profile will be presented. Then the CREATOUR project in Portugal and in the Alentejo region is outlined. Next, the adopted methodology will be described, with focus on the research setting, data collection, and analysis together with the findings. Finally, the paper ends with some practical contributions, limitations, and suggestions for further research.

\section{Tourist experiences in creative tourism contexts: brief approach}

\subsection{Creative tourism concept}

One of the first definitions of creative tourism derives from the EUROTEX project undertaken between 1996 and 1999 in Finland, Greece and Portugal and was presented by Greg Richards and Crispin Raymond, as follows: "Tourism which offers visitors the opportunity to develop their creative potential through active participation in courses and learning experiences which are characteristic of the holiday destination where they are taken" [1]. For UNESCO [2] creative tourism explores, more meaningfully and genuinely, the interaction between the visitor and the host community. In the context of the Creative Cities Network, UNESCO advanced the following definition: "Creative tourism is travel directed toward an engaged and authentic experience, with participative learning in the arts, heritage, or special character of a place and it provides a connection with those who reside in this place and create this living culture" [2]. Sometime later, Crispin Raymond presented a revised definition: "A more sustainable form of tourism that provides an authentic feel for a local culture through informal, hands-on workshops and creative experiences. Workshops take place in small groups at tutors' homes and places of work; they allow visitors to explore their creativity while getting closer to local people" [3]. Although some earlier concepts of creative tourism make reference to learning experiences linked to traditional areas of culture and creativity [4;5], more recent approaches integrate tourism with creative industries (e.g. design, fashion, and gaming), creative cities, creative districts or places as a whole, among other emerging approaches. As result, the trend for involvement between consumers, producers, policy makers and knowledge institutions, providing access to new markets and diversifying demand has been increasing [1,4]. 